\title{
SCALP RECONSTRUCTION WITH THREE RHOMBOID FLAPS AFTER SQUAMOUS CELL CARCINOMA EXCISION
}

\author{
Catalin G. BEJINARIU1 ${ }^{1}$, Romana MANESCU ${ }^{1}$, Laura M. BOGHIAN ${ }^{1}$, \\ Matei GHEORGHIU - BRANARU ${ }^{1}$, Siramona POPESCU ${ }^{1}$, Silviu A. MARINESCU ${ }^{1}$
}

${ }^{1}$ Department of Plastic and Reconstructive Surgery, „Bagdasar-Arseni“ Emergency Clinical Hospital, Bucharest, Romania

Received 03 Apr 2020, Corrections received 21 Apr 2020, Accepted 05 May 2020

https://doi.org/10.31688/ABMU.2020.55.2.18

\begin{abstract}
Introduction. Scalp tumours raise multiple problems regarding the radical excision of the neoplasm followed by reconstructive surgery. Prolonged sun exposure and administration of immunosuppressive medication are the main risk factors for the onset of this neoplasm. The paper presents the advantages and disadvantages of scalp reconstruction using rhomboid flaps, after surgical excision of the skin cancer.

Case presentation. The paper presents the case of a 83-year-old patient admitted for the treatment of squamous cell carcinoma located on the scalp. The pathological history of the patient showed that there were multiple hospitalizations for the treatment of chronic heart failure and hypertension. The therapeutic protocol included excision of a squamous cell carcinoma located in the scalp, followed by immediate reconstruction with three rhomboid flaps advanced towards the midline. The local evolution of the patient was favorable, the flaps integrating without complications, obtaining in this context a very good result from an aesthetic point of view.
\end{abstract}

Conclusions. The use of the reconstructive technique involving the transposition of three rhomboid flaps to cover the soft tissue defects located in the scalp

\section{Résumé}

Reconstruction du cuir chevelu à l'aide de trois lambeaux rhomboïdes après l'excision du carcinome cellulaire squameux

Introduction. Les tumeurs du cuir chevelu posent de multiples problèmes en termes de réalisation d'un traitement radical d'ablation puis de chirurgie reconstructive. Dans cet article, on présente les avantages et les désavantages de la reconstruction de l'épicrâne en utilisant de lambeaux rhomboïdes, après l'excision des tumeurs cutanées. Une exposition prolongée au soleil et l'administration d'immunosuppresseurs sont les principaux facteurs de risque d'apparition de ce néoplasme.

Présentation de cas. L'étude expose le traitement chirurgical reconstructif chez un patient de 83 ans admis dans notre service pour le traitement d'un néoplasme squamo-cellulaire au niveau du vertex. Parmi les antécédents médicaux du patient, il y a eu plusieurs hospitalisations pour le traitement d'une insuffisance cardiaque chronique et de l'hypertension artérielle. Le protocole thérapeutique a inclus l'excision de la tumeur squamo-cellulaire localisée au niveau de l'épicrâne, suivie de la reconstruction immédiate à l'aide de trois lambeaux rhomboïdes avancés vers la 
region is a feasible solution that offers very good aesthetic results.

Keywords: scalp tumour, rhomboid flap, squamous cell carcinoma, skin cancer.

\section{INTRODUCTION}

Scalp tumours raise multiple problems in terms of performing excisional radical treatment and then reconstructive surgery ${ }^{1}$. The treatment is represented by the achievement of complete tumour excision respecting the oncological safety margins ${ }^{2}$. Frequently, the complete excision leads to a large soft tissue defect. Since postoperative scar sequelae located at the level of the cephalic extremity are difficult to tolerate by patients, special attention should be paid to the selection of the optimal reconstructive technique, that will allow the best aesthetic result under the conditions of an increased safety profile ${ }^{3.5}$.

\section{Case presentation}

We report the case of an 83-year-old patient admitted to the „Bagdasar - Arseni“ "Clinical Emergency Hospital, Bucharest, Romania, for the treatment of a scalp tumour. The tumour appeared approx. 2 years prior to hospital admittance and gradually increased in size until the time of the medical consult. The personal medical history was marked by multiple hospitalizations for the treatment of cardiac pathology, the patient suffering from chronic heart failure and high ligne médiane. L'évolution locale du patient a été favorable. Les lambeaux ont été intégrés sans complications, obtenant dans ce contexte un résultat esthétique très satisfaisant.

Conclusions. L'utilisation de trois lambeaux rhomboïdes transposés pour le couvrement des défauts des parties molles au niveau de l'épicrâne est une solution faisable, qui offre de très bons résultats esthétiques.

Mots-clés: tumeur du cuir chevelu, lambeau rhomboïde, carcinome squamo-cellulaire, cancer de la peau.

blood pressure, conditions that were under medical control at the time of the surgery.

The local examination revealed the presence of an irregularly shaped tumour, the lesions being included in a circle with a diameter of about $1.5 \mathrm{~cm}$. The tumour had a hard consistency and a high degree of mobility on the subjacent anatomical structure. The patient did not have perilesional sensory impairment.

Following the analysis of the paraclinical investigations and the local examination, it was decided to perform the excision of the tumour, followed by intraoperative histopathological examination and immediate reconstruction using three rhomboid flaps. To reduce the risks associated with general anesthesia, the surgery was performed with local anesthesia.

The flap dissection was facilitated by the existence of the preoperative drawing, an extremely important element in this type of reconstruction. Respecting the dimensions and angles of the flaps is essential for the smooth coverage of the postexcision defect (Fig. 1).

The surgical intervention lasted 90 minutes, the excision being performed according to the preoperative marking and the tumour was sent to the department of pathological anatomy for intraoperative
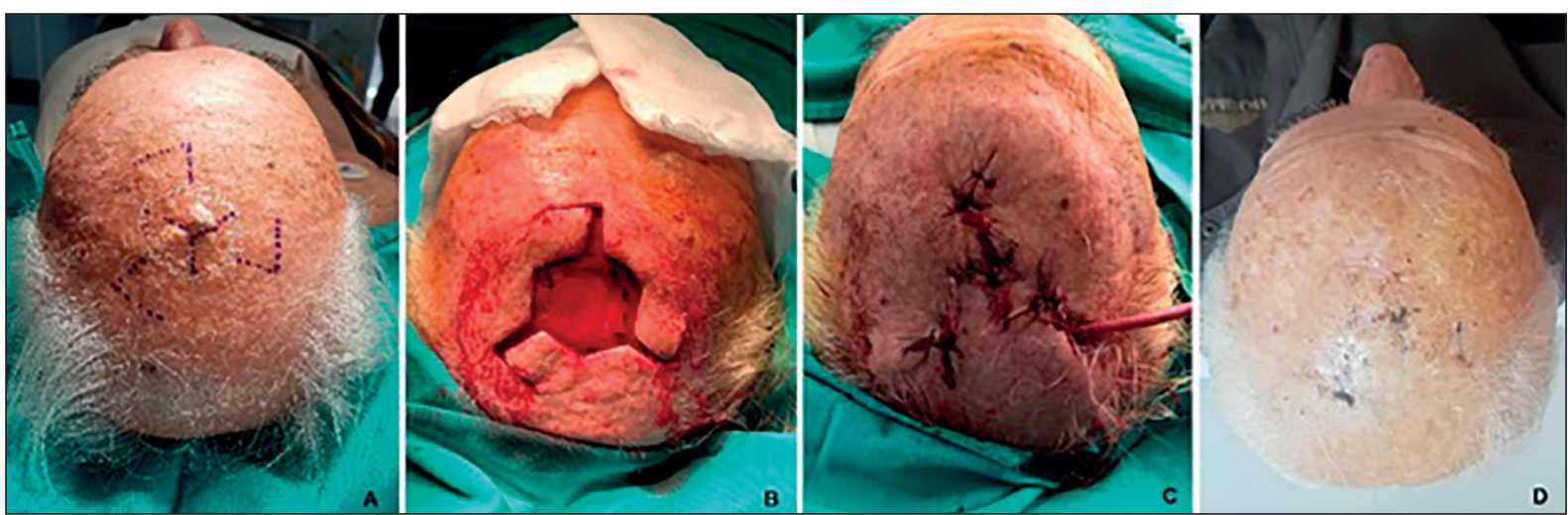

Fig. 1. Stages of the surgery. A. Preoperative drawing; B. Flap dissection;

C. Postoperative aspect after the reconstruction; D. Postoperative aspect after 3 weeks 
histopathological examination. The result of the examination showed that the tumour had histological characteristics of squamocellular carcinoma. After receiving the result, the surgical intervention continued with the dissection of the three rhomboid flaps and their transposition to the median line in order to cover the remaining defect resulted from the removal of the neoplasm.

No complications were identified during surgery, however due to the increased bleeding risk caused mainly by the cardiological medication, an aspiration drain was fitted at the end of the operation.

The patient was discharged 24 hours after surgery, the sutures being removed 14 days after the intervention. Postoperative monitoring was performed for 12 months (Fig. 2), the medical consultations being carried out every 3 months.

\section{Discussion}

According to the specialized literature, the incidence of the squamous cell carcinoma is increasing worldwide. Statistics in the United States show that the risk of occurence of this condition during lifetime is between 9 and $14 \%$ for men, while for the female population the values vary between $4 \%$ and 9\%. Annually, United States report between 200,000 and 400,000 new cases of squamous cell carcinoma,

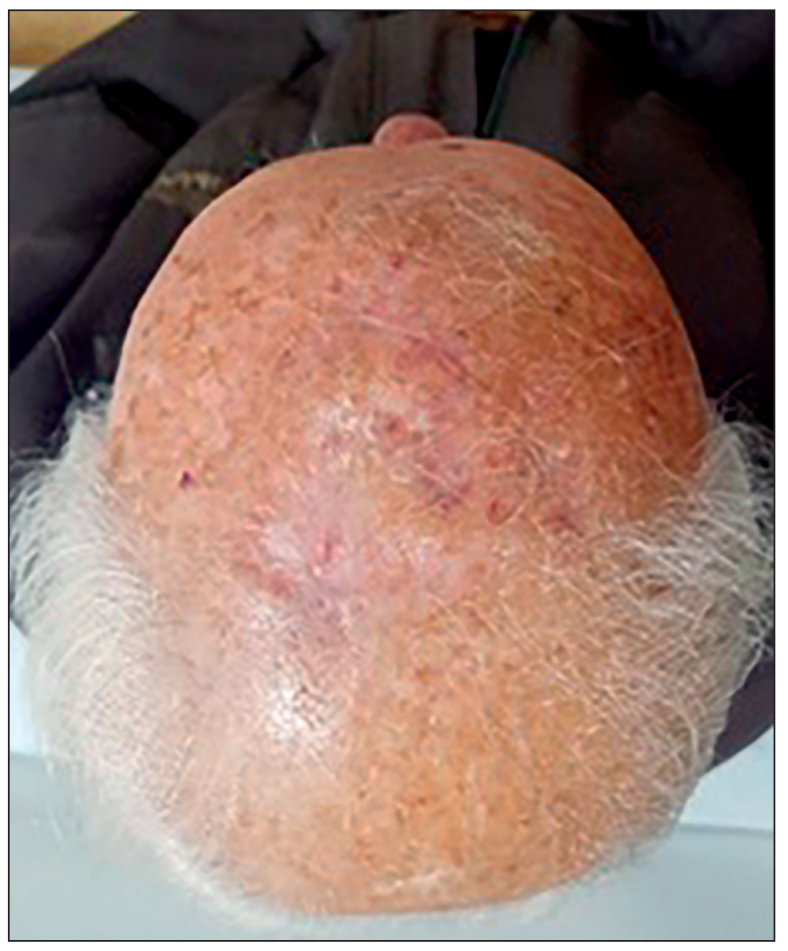

Fig. 2. Postoperative aspect 12 months after the reconstructive surgery. as well as 3000 deaths associated with this type of neoplasm ${ }^{6-9}$.

Radical excision is the main objective of the surgery dedicated to the treatment of cutaneous neoplasms. The size of the tumour, its location and the associated diseases are the main elements that contribute to the increased degree of difficulty of these surgical interventions. Reconstruction of scalp defects by using three rhomboid flaps is recommended in case of lesions of small and moderate dimensions, the use of this technique often being associated with local complications, such as necrosis and dehiscence $^{10-13}$. Atraumatic manipulation of the flaps is an essential element that contributes equally to accelerating the healing process and reducing immediate postoperative complications, such as necrosis.

Performing the intraoperative histopathological examination is an element that significantly improves the safety profile of this type of intervention, offering a correct overview of the reconstructive options $s^{14-16}$. When it is mandatory to perform an additional excision that could affect the initial preoperative marking, the careful measuring and intraoperative markings represent elements that can significantly contribute to the reduction of the postoperative complications; special attention should be given to the fact that the reduced flexibility of the tegument does not allow the correction of possible dissection errors.

The rich vascular supply of the scalp represents a positive prognostic factor, which contributes to the decrease of the risk related to the necrosis of the flaps and to the acceleration of the healing process ${ }^{16-17}$. However, it should not be neglected that the achievement of a rigorous hemostasis is an essential element that prevents the occurence of the bleeding complications ${ }^{18}$. In this context, monitoring the aspiration drainage can be the optimal solution, its supression 24 hours after the surgical intervention lowering the risks related to immediate postoperative complications ${ }^{19}$.

An element that contributes to the wound closure at the end of the reconstructive intervention is represented by the performance of a hexagonal excision that allows the ideal closure of the flap margins. The circular excision of the tumour is associated with suture errors that can lead to dehiscences and delayed healing.

Regarding alternative reconstructive techniques, time has confirmed the feasibility of rotated and transposed scalp flaps. However, it should not be overlooked that the large dimensions of these flaps require extensive dissections, often performed under general anesthesia ${ }^{20}$. Another negative element is that the donor area has to be covered by split thickness skin grafts that involves the injury of another anatomical regions, a factor that contributes to the 
decrease of the patient's satisfaction with regard to the surgical experience.

\section{Conclusions}

The use of the reconstructive technique that involves covering the scalp defects by using three rhomboid flaps represents a firm solution for covering small and moderate scalp defects using local anesthesia.

This reconstructive technique allows the patient to be discharged 24 hours after surgery, the treatment being continued in an ambulatory regime. Moreover, this type of reconstruction is associated with an increased patient's satisfaction and a favorable aesthetic result.

\section{Author Contributions:}

B.C., B.L., and M.R. were responsible for the diagnostic procedures, clinical diagnosis, and treatment decisions. B.C., P.S., G.M., and M.S. wrote the manuscript. All authors have read and agreed to the published version of the manuscript.

\section{Compliance with ethics requirements:}

„The authors declare no conflict of interest regarding this article."

"The authors declare that all the procedures and experiments of this paper respect the ethical standards in the Helsinki Declaration of 1975, as revised in 2008(5), as well as the national law. Informed consent was obtained from the patient presented."

„No funding for this research."

\section{Acknowledgments:}

None

\section{RefERENCES}

1. Ehrl D, Brueggemann A, Broer PN, Koban K, Giunta R, Thon N. Scalp reconstruction after malignant tumor resection: an analysis and algorithm. J Neurol Surg B. 2020;81(02):149-157.

2. Steiner D, Hubertus A, Arkudas A, et al. Scalp reconstruction: A 10-year retrospective study. Journal of Cranio-Maxillofacial Surgery. 2017;45(2):319-324.

3. Varnalidis I, Mantelakis A, Spiers HVM, Papadopoulou AN. Application of the pinwheel flap for closure of a large defect of the scalp. BMJ Case Reports CP. 2019;12:e229420.
4. Ellis M, Hwang L, Ford NK, Slavin K. The role of the visor flap in scalp reconstruction: a case series of $21 \mathrm{pa}$ tients. Operative Neurosurgery. 2018;15(6):651-655.

5. Altun S, Cakır F, Öztan M, Okur ZMI, Bal A. Do rhomboid flaps provide more elongation than Z-plasty flaps? An experimental study. Journal of Plastic Surgery and Hand Surgery 2018;52(3):148-152.

6. Lok TungHo C,Visavadia B, Shah K, Deshmukh M. Periorbital squamous cell carcinoma with simultaneous adenocarcinoma in the right orbit. International Journal of Surgery Case Reports. 2020;67:187-190.

7. Ali L, Moldovan V, Derewicz D, Ginghina O, Sajin M, Costache M. Metastatic melanoma presenting as undifferentiated tumor of unknown primary site: an immunohistochemical algorithm. Arch Balk Med Union. 2019;53(4):672-679.

8. Kim JYS, Kozlow JH, Mittal B, et al. Guidelines of care for the management of cutaneous squamous cell carcinoma. J Am Acad Dermatol. 2018;78(3):560-578.

9. Marur S, Forastiere AA. Head and neck squamous cell carcinoma: update on epidemiology, diagnosis, and treatment. Mayo Clinic Proceedings. 2016;91(3):386-396.

10. Bejinariu C, Giuglea C, Marinescu S. Complex facial reconstruction using local anesthesia - case presentation. Romanian Journal of Medical Practice. 2019;3(67):321-324.

11. Kim YH, Kim GH, Kim SW. Reconstruction of a complex scalp defect after the failure of free flaps: changing plans and strategy. Arch Craniofac Surg. 2017;18(2):112-116.

12. Vogt PM, Mett TR, Broelsch GF. Interdisciplinary reconstruction of oncological resections at the skull base, scalp and facial region. Surgical Oncology. 2017;26(3): 18-323.

13. Costa DJ, Walen S, Varvares M. Scalp rotation flap for reconstruction of complex soft tissue defects. J Neurol Surg B. 2016;77(01):032-037.

14. Tomljanovich P, Ozturk CN. Reconstruction of face and scalp defects with local flaps, contemporary oral oncology. Springer, 2017: 211-233.

15. Simsek T, Eroglu L. Versatility of the pinwheel flap to reconstruct circular defects in the temporal and scalp region. Journal of Plastic Surgery and Hand Surgery. 2013;47(2):97-101.

16. Li G, Mu L, Bi Y, et al. Pacman flap for oncologic reconstruction of soft-tissue defects after tumor resection: A retrospective case series. Medicine (Baltimore). 2018; 97(25):e11114.

17. Bejinariu C, Marinescu S. The role of myocutaneous flaps in the treatment of patients with multiple decubitus ulcers. Journal of Medicine and Life. 2019;12(4):453-456.

18. Laslo C, Pantea Stoian A, Socea B, et al. New oral anticoagulants and their reversal agents. Journal of Mind and Medical Sciences. 2018;5(2):195-201.

19. Jun P, Lee SJ, Jun K. Bilateral Burrow's grafts with a pulley suture: Rapid and simple reconstruction for a large defect on the vertex. Indian Journal of Dermatology, Venereology and Leprology. 2019;85(4):428-430.

20. Tiglis M, Neagu TP, Elfara M, et al. Nefopam and its role in modulating acute and chronic pain. Rev Chim. 2018;69(10): $2877-2880$ 